\title{
UNDERSTANDING THE DISTRIBUTION OF THREE SPECIES OF EPIPHYTIC ORCHIDS IN TEMPERATE AUSTRALIAN RAINFOREST BY INVESTIGATION OF THEIR HOST AND FUNGAL ASSOCIATES
}

\author{
Kelli M. Gowland ${ }^{1,3,4}$, Ulrike Mathesius ${ }^{2}$, Mark A. Clements ${ }^{3}$ \\ $\&$ ADRIENNE B. NICOTRA ${ }^{1}$ \\ ${ }^{1}$ School of Botany and Zoology, Australian National University, Bldg 116 Daley Road, \\ Canberra, A.C.T. 0200, Australia \\ ${ }^{2}$ School of Biochemistry and Molecular Biology, Australian National University, Bldg 41 Linnaeus Way, \\ Canberra, A.C.T. 0200, Australia \\ ${ }^{3}$ Centre for Plant Biodiversity Research, Australian National Herbarium, CSIRO Division of Plant Industry, \\ GPO Box 1600, Canberra, A.C.T. 2601, Australia \\ ${ }^{4}$ Author for correspondence: kelli.gowland@anu.edu.au
}

KeY words: epiphyte, Aeridinae, orchid mycorrhizal fungi, Ceratobasidium, chemotropism

\section{Introduction}

Understanding the environmental constraints that affect species distributions are critical to the maintenance of biodiversity. The abundance of epiphytic organisms, those that grow on another substrate, such as a tree or rock, is a direct consequence of the availability and distribution of these substrates (Ackerman et al. 1989). In the case of epiphytic orchids it is also due to the presence of orchid mycorrhizal fungi (OMF). For an orchid, crucial to its germination and establishment, is its association with an OMF. The OMF provides a carbon source to the developing orchid embryo (Rasmussen 1995). Although reciprocal carbon transfer has been demonstrated in mature plants of a green, terrestrial, orchid species, Goodyera repens (Cameron et al. 2006), it is generally believed that OMF receive no immediate benefit from their association with orchids. Therefore, it would appear intuitive that orchids would associate with all OMF available within their local environment and that they would actively seek this association.

In this investigation we sought to ascertain the nature of the relationship between three closely related, co-occurring species of epiphytic, Aeridinae (= Sarcanthinae) orchids, their OMF, and their phorophytes (host trees). The orchid study species: Sarcochilus hillii, Sarcochilus parviflorus and Plectorrhiza tridentata are all small, monopodial epi- phytes found on trees and shrubs in temperate rainforest gullies. The null hypothesis that we are testing is that these three orchid species are randomly distributed throughout their forest habitat.

More specifically we are addressing the following questions:

- Do these three epiphytic orchid species exhibit a random distribution across the woody plants of the forest?

- Do these three orchid species associate with all OMF within their local environment?

- Do the OMF of these orchid species differ in their ability to stimulate germination amongst these species?

- Are these OMF actively attracted towards the seed of these three orchid species?

\section{Methods}

To address these questions we surveyed four sites where these three orchid species co-occur in temperate south-eastern Australia. The woody plant composition of the forests and the associations of these three orchid species with their phorophytes were determined using a maximum likelihood model. Generalised Linear Mixed Models (GLMMs) were used to detect preferences for physical features of the phorophyte and local environment of these orchid species. 
To ensure adequate sampling of the OMF of each orchid species, ten members of each species were surveyed from two sites. To investigate the diversity of OMF on the preferred phorophyte, five orchids that were sampled of each species were on the most common host. Earlier research indicated that other members of these orchid genera associated with the Ceratobasidiaceae within the form-genus Rhizoctonia (Warcup 1981). We also targeted Rhizoctonia-like fungi when we isolated OMF from the roots of these orchids. Verification that the isolated fungi were capable of stimulating orchid germination (and therefore, were indeed OMF) was determined by germination trials. Genetic identification of the fungal associates was conducted by sequencing the nuclear ribosomal internal transcribed spacer (Gardes \& Bruns 1993) and the mitochondrial large subunit (White et al. 1990), and through the amplification of dispersed repetitive DNA sequences (Versalovic et al. 1991). Finally, to determine if the fungi were actively attracted towards orchid seed, chemotropism trials were conducted and the amount of fungal growth towards test and control aliquots (of seed and water respectively) was compared using Paired t-tests.

\section{Results and discussion}

Backhousia myrtifolia was the most common tree at most sites and was the dominant phorophyte species for all three orchid species, significantly so for S. parviflorus and P. tridentata. All three orchid species preferred a phorophyte with moderate to high moss cover. Despite these similarities, distinct differences in the distribution patterns were detected for each species of orchid.

These three orchid species differed in the composition of their phorophyte flora: $S$. hillii's distribution approximated a random distribution which reflected that of the rainforests' tree species composition; $P$. tridentata exhibited a strong bias towards B. myrtifolia, although was otherwise on the broadest range of phorophyte species; and $S$. parviflorus had the narrowest range of phorophytes, exhibiting clear preferences for and against particular woody plant species. However, the 'species' of phorophyte was not the only correlate with orchid presence, each orchid species exhibited non-random patterns in their prox- imity to moss and location on their phorophytes. Characteristics of the phorophyte that had the greatest effect on the size and reproductive potential of the orchids, as measured by the size and number of leaves and number of inflorescences, were independent of the species of the phorophyte.

We expected that these distributional differences would reflect distinct OMF associations with each orchid species; however, whilst different OMF were found in association with these orchids it has not explained the difference in phorophyte species association. All OMF isolated from these three orchid species belonged to two distinct clades, groups, within the genus Ceratobasidium, recognised as clade L and clade K. All three orchid species associated with clade $\mathrm{K}$, but only $S$. hillii was found with clade L. This did not, however, explain the random distribution of $S$. hillii, as members of both fungal clades were isolated from orchids on the common phorophyte, B. myrtifolia. Additionally, germination trials revealed that even though both groups of fungi were not naturally found in association with $S$. parviflorus and P. tridentata, members of each $\mathrm{OMF}$ clade could stimulate germination in all three orchid species ex situ.

Furthermore, the chemotropism experiment revealed that members of both OMF clades were attracted towards viable orchid seed. This is the first experiment, that we know of, that has demonstrated that orchid mycorrhizal fungi is actively attracted to orchid seed.

\section{Conclusion}

Each orchid species clearly demonstrated characteristic preferences for phorophyte species or features, indicative of specific ecological niches. They did not exhibit a random distribution throughout the forest. Furthermore, despite exposure to multiple potential OMF, S. parviflorus and P. tridentata were only found in association with a restricted subset of those available in their local environment. This is despite $e x$ situ results indicating that there is no inherent physiological reason why they do not associate with both groups of OMF, and the fact that both clades of fungi are actively attracted to orchid seed.

These results typify the intrigue around this family 
of plants. For example, why would $S$. parviflorus and $P$. tridentata attract, but not utilise all OMF within their ecosystem? Possible explanations and ideas for further study will be discussed.

ACKNOWLEDGMENTS. We gratefully acknowledge the financial support of the American Orchid Society, the Australian National University and the CSIRO in funding this research, and the Australian Orchid Foundation and the Australian Biological Resources Study in their assistance with attending this conference. We would also like to thank: J. Wood for his assistance with the analysis of the ecological data; M. van der Merwe, C. Linde, B. Pfeil, T. Otero and R. Bayer for their advice in deciphering the identity of these OMF; and to S. Refshauge and the CSIRO microscopy unit for technical advice on the microscopy and chemotropism experiments.

\section{LITERATURE CITED}

Ackerman, J.D., A.M. Montalvo \& A.M. Vera. 1989. Epiphyte host specificity of Encyclia krugii, a Puerto Rican endemic orchid. Lindleyana 4: 74-77.
Cameron, D.D., J.R. Leake \& D.J. Read. 2006. Mutualistic mycorrhiza in orchids: evidence from plant-fungus carbon and nitrogen transfers in the green-leaved terrestrial orchid Goodyera repens. New Phytol. 171: 405-416.

Gardes, M. \& T.D. Bruns. 1993. ITS primers with enhanced specificity for basidiomycetes - application to the identification of mycorrhizae and rusts. Mol. Ecol. 2: 113-118.

Rasmussen, H.N. 1995. Terrestrial Orchids from seed to mycotrophic plant. Melbourne, Australia, Cambridge University Press.

Versalovic, J., T. Koeuth \& J.R. Lupski. 1991. Distribution of repetitive DNA sequences in eubacteria and application to fingerprinting of bacterial genomes. Nucl. Acids Res. 19: 6823-6831.

Warcup, J.H. 1981. The mycorrhizal relationships of Australian orchids. New Phytol. 87: 371-381.

White, T.J., T. Bruns, S. Lee \& J. Taylor. 1990. Amplification and direct sequencing of fungal ribosomal RNA genes for phylogenetics. In: M.A. Innis, D.H. Gelfand, J.J. Sninsky \& T.J. White (eds.), PCR Protocols: A guide to methods and applications. San Diego, Academic Press.

Kelli Gowland is a PhD candidate at the Australian National University, and CSIRO - Plant Industry in Canberra, Australia. Kelli's main interest is in evolutionary ecology and has had field experience in South Africa, Cape York and the Kimberleys as well as throughout southeastern Australia. Kelli conducted her honours research on the ecological factors maintaining species boundaries in two species of hybridising alpine Ranunculus and has had field experience in South Africa, Cape York and the Kimberleys. Kelli's current research is into the ecological distribution of three epiphytic orchids in Australia and she has uncovered some valuable clues that may aid in understanding the evolution of the relationship between orchids and their mycorrhizal fungi. 